\title{
Caracterización, por RAPD-PCR, de aislados de Pseudomonas aeruginosa obtenidos de pacientes con fibrosis quística
}

\author{
Maribel O rtiz-Herrera, Q FB, ${ }^{(1)}$ Armando G erónimo-Gallegos, Q FB, ${ }^{(1)}$ Francisco Cuevas-Schacht, MD, ${ }^{(2)}$ \\ Lorenzo Pérez-Fernández, MD, (2) Rafael Coria-jiménez, Q BP, Dr en C.(1)
}

\section{Ortiz-Herrera M, Gerónimo-Gallegss A, Cuevas-Schacht F, Pérez-Fernández L, Coria-Jiménez $R$. Caracterización, por RAPD-PCR, deaisladosde Pseudomonasaeruginosa obtenidos de pacientes con fibr osisquística. Salud Publica Mex 2004;46:149-157.}

El texto completo en inglés de este artículo está disponible en: http://www.insp.mx/salud/index.html

\section{Resumen}

Objetivo. C aracterizar a las cepas de $P$ aeruginosa aisladas de lavados broncoalveolares de pacientes con fibrosis quística a lo largo de un periodo de tres años. Material y métodos Estudio prospectivo, de seguimiento de una población de pacientes con fibrosis quística. Se utilizó la técnica de la amplificación del AD N empleando PCR con bajas condiciones de especificidad (Random amplified polymorphic DNA, RAPD-PCR) para la amplificación del ADN de cepas de $P$ aeruginosa aisladas de lavados bronco alveolares de cinco pacientes con fibrosis quística, provenientes del Servicio de Neumología y Cirugía del Tórax del Instituto $\mathrm{N}$ acional de Pediatría de la Ciudad de México, en el periodo de junio de 1996 a junio de 2002; se establecieron los patrones de amplificación de cada aislamiento, lo que permitió la identificación precisa de todas las cepas aisladas y el estudio de la epidemiología de P aeruginosa en los pacientes seleccionados con dicha enfermedad. Resultados. Se definieron 18 patrones de amplificación del ADN que permitieron identificar a cada cepa de $P$ aeruginosa aislada en las diferentes muestras de lavado broncoalveolar; no se encontró relación entre el fenotipo de $P$ aeruginosa (mucoide 0 no mucoide) y el genotipo de cada aislamiento, ya que cepas con fenotipos distintos mostraron patrones de amplificación semejantes; en nuestros pacientes se identificaron cepas con patrones de amplificación distintos a partir

\author{
Ortiz-Herrera M, Gerónimo-Gallegs A, Cuevas-Schacht F, \\ Pérez-Fernández L, Coria-Jiménez R. \\ RAPD-PCR characterization \\ of Pseudomonasaeruginosa strains \\ obtained fr om cystic fibr osis patients. \\ Salud Publica Mex 2004;46:149-157. \\ The English version of this paper \\ is available at: http://www.insp.mx/salud/index.html
}

\begin{abstract}
A bstract
Objective.To characterize $P$ aeruginosa strains iso lated from bronchoalveolar lavage fluid of cystic fibrosis (CF) patients over a 3 year period. Material and Methods. A prospective follow-up study was carried out in a po pulation of cystic fibrosis patients. The random amplified polymorphic D N A (RAPD) technique was used to amplify DNA of P aeruginosa strains isolated from bronchoalveolar lavage fluid samples of five CF patients from the Servicio de $\mathrm{Neu}$ mología y Cirugía del Tórax del Instituto $\mathrm{N}$ acional de Pediatría (Mexico C ity Chest $\mathrm{Clinic}$ of the $\mathrm{N}$ ational Pediatrics Institute) in Mexico City, between June 1996 and June 2002. A mplification patterns were established for each isolate to accurately identify all strains and to carry out an epidemiological analysis of $P$ aeruginosa among the selected CF patients. Results. Eighteen different DN A amplification patterns were defined and used to identify each $P$ aeruginosa strain isolated from the different bronchoalveolar lavage samples. No correlation was observed between the different $P$ aeruginosa strain genotypes and mucoid or nonmucoid phenotypes, as strains with different phenotypes showed similar amplification patterns. Several strains with different amplification patterns were identified in samples obtained from the same patient, suggesting coinfection with more than one $P$ aeruginosa strain. Two siblings with CF shared similar genotypes, suggesting the occurrence of cross-
\end{abstract}

(1) Laboratorio de Bacteriología Experimental, Instituto N acional de Pediatría, Secretaría de Salud (SSA), México, DF, México.

(2) Servicio de N eumología y Cirugía de Tórax, Instituto N acional de Pediatría, SSA, México, D F, México.

Fecha de recibido: 20 de junio de 2003 - Fecha de aprobado: 19 de enero de 2004 Solicitud de sobretiros: Dr. Rafael Coria Jiménez. Laboratorio de Bacteriología Experimental, Instituto N acional de Pediatría. Insurgentes Sur 3,700-C, colonia Cuicuilco-Universidad 04530, México, D F, México. Correo electrónico: rafaelcoria@ yahoo.com 
de una misma muestra, lo que sugiere la presencia de infecciones simultáneas por más de una cepa de $P$ aeruginosa; se demostró que dos hermanos con la enfermedad compartían cepas con genotipos semejantes, lo que sugiere una contaminación cruzada entre ambos, y se demostró el aislamiento de cepas de $P$ aeruginosa con genotipos semejantes a lo largo de los periodos estudiados. Conclusiones La identificación mediante la caracterización genotípica de las cepas de $P$ aeruginosa aisladas de los pacientes con fibrosis quística permite llevar a cabo estudios más precisos de la epidemiología de esta importante relación huésped-parásito. El texto completo en inglés de este artículo está disponible en: http://www.insp.mx/salud/index.html

Palabras clave: Pseudomonas aeruginosa; fibrosis quística; técnica del ADN polimorfo amplificado aleatorio; México contamination. Similar genotypes of $P$ aeruginosa strains were isolated throughout the study period. Conclusion. Genotypic characterization of $\mathrm{P}$ aeruginosa strains in $\mathrm{CF}$ patients allows more accurate epidemiological analyses of this important host-agent relationship. The English version of this paper is available at: http://www.insp.mx/salud/index.html

Key words: Pseudomonas aeruginosa; cystic fibrosis; random amplified polymorphic D N A technique; Mexico
$P^{s}$ seudomonas aeruginosa es una bacteria aeróbica, no formadora de esporas, Gram negativa, móvil, debido a la presencia de flagelos polares, positiva a las pruebas de oxidasa y catalasa, que pertenece al grupo heterogéneo denominado "no fermentadores"; esta bacteria se considera como un microrganismo patógeno oportunista, capaz de desarrollar procesos infecciosos en pacientes inmunocomprometidos o que tienen problemas de fondo en sus mecanismos homeostáticos. ${ }^{1,2}$

Ha sido descrita ampliamente la estrecha relación entre $P$ aeruginosa y los pacientes con fibrosis quística (FQ) quienes de manera característica presentan procesos infecciosos crónicos por esta bacteria, que finalmente conducen a la muerte del paciente debido a las complicaciones derivadas de la infección bacteriana y a una respuesta exacerbada de los mecanismos de defensa del huésped frente a esta infección crónica. ${ }^{1-5}$

$P$ aeruginosa posee distintos factores de virulencia y se ha demostrado que las condiciones del medio ambiente como la tensión de $\mathrm{O}_{2}$, la disponibilidad de hierro y la presencia de antibióticos son factores que modulan la síntesis y la función de estos factores bacterianos. ${ }^{4,5}$

En el caso de la relación de $P$ aeruginosa con el paciente con FQ, la bacteria posee receptores que interaccionan de manera específica con la proteína cystic fibrosis transmembrane conductance regulator (CFTR) y es capaz de adaptarse a las condiciones del tracto respiratorio de estos pacientes, condiciones que seleccionan a las clonas bacterianas más eficientes en términos de adaptación frente a este medio ambiente agresivo.

Como respuesta a las condiciones del tracto respiratorio de los pacientes con FQ, P aeruginosa produce una gran cantidad de alginato lo que conduce a la pre- sentación del fenotipo bacteriano mucoide, característico de las cepas asociadas a FQ y, adicionalmente, el microrganismo cambia su perfil de proteínas de membrana, pierde flagelos convirtiéndose en inmóvil, modula la síntesis del liposacárido bacteriano (LPS), crece formando biopelículas o microcolonias, modifica su velocidad de crecimiento celular, etcétera. ${ }^{1-5}$

Debido a esta capacidad de adaptación de $P$ aeruginosa, los sistemas habituales empleados en el laboratorio para la identificación y caracterización microbiana no poseen la suficiente sensibilidad y especificidad para establecer con certeza la identidad de un aislado bacteriano, por lo que ha sido necesario desarrollar o adaptar sistemas de caracterización genotípica, que sean capaces de identificar y caracterizar de manera precisa a estos microrganismos a pesar de cualquier modificación en el fenotipo.

A la fecha se han descrito distintos sistemas genotípicos destinados a la caracterización de aislados de $P$ aeruginosa obtenidos de pacientes con FQ; sistemas como la hibridización con sondas específicas y la electroforesis de campos pulsados han demostrado ser sensibles y específicos, sin embargo, presentan como inconvenientes el costo elevado de ambos y el prolongado tiempo de realización. ${ }^{6-17}$

Un sistema adicional utilizado para la identificación de $P$ aeruginosa es el de la reacción en cadena de la polimerasa (PCR), del que se han descrito distintas metodologías dependiendo de los objetivos y condiciones del ensayo. Una de tales adaptaciones es la amplificación del ADN empleando PCR con bajas condiciones de especificidad (Random amplified polymorphic $D N A, R A P D-P C R)$; en este caso se emplean iniciadores (primers) de baja especificidad que se alinean de manera aleatoria con secuencias presentes a lo largo del 
genoma bacteriano, una vez estandarizado el sistema RAPD-PCR permite la obtención de patrones de amplificación reproducibles y característicos de cepas o clonas. $^{18,19}$

La técnica de la amplificación del ADN empleando PCR con bajas condiciones de especificidad (RAPDPCR, por sus siglas en inglés) ha sido empleada con el propósito de estudiar la relación huésped-parásito entre $P$ aeruginosa y los pacientes con $\mathrm{FQ}$, principalmente en el aspecto epidemiológico para estudio de la prevalencia de las diferentes cepas en familias de éstos, así como para identificar infecciones cruzadas y reinfecciones por esta bacteria. ${ }^{20-26}$

Con el propósito de caracterizar a los aislados de $P$ aeruginosa obtenidos de pacientes con FQ se utilizó la reacción en cadena de la polimerasa en condiciones de baja especificidad (RAPD-PCR) utilizando dos iniciadores arbitrarios; la utilización de RAPD-PCR nos permitió identificar cepas aisladas de muestras sucesivas de lavado broncoalveolar para el análisis de la epidemiología de $P$ aeruginosa en los enfermos de FQ que acudieron al Servicio de Neumología y Cirugía de Tórax del Instituto Nacional de Pediatría durante el periodo comprendido de septiembre de 1996 a julio de 2000.

\section{Material y métodos}

Pacientes con fibrosis quística. Las muestras clínicas a partir de las cuales se aisló $P$ aeruginosa fueron obtenidas de 64 pacientes con FQ del Servicio de Neumología y Cirugía de Tórax del Instituto Nacional de Pediatría (SNCT-INPed).

A partir de 1996 iniciamos un proyecto donde se estudia la asociación entre $P$ aeruginosa y nuestros pacientes con FQ; como parte de tal proyecto se ha evaluado la utilidad del lavado broncoalveolar como un método para la obtención de muestras para el aislamiento bacteriano; en la actualidad el lavado broncoalveolar es parte del tratamiento al cual se somete a estos pacientes con el propósito de descongestionarles el tracto respiratorio y disminuirles las molestias. ${ }^{27}$

Obtención de la muestra. A los pacientes con FQ se les practicaron lavados broncoalveolares sucesivos; para ello se utilizaron fibrobroncoscopios Olympus 3.5 en los pacientes menores de dos años de edad y de $4.7 \mathrm{~mm}$ en el resto; la muestra de aspirado broncoalveolar se tomó llevando la punta del fibrobroncoscopio al lóbulo medio e instilando $5 \mathrm{ml}$ de solución salina fisiológica estéril; el material recuperado se colocó en un frasco estéril y se envió al laboratorio para su procesamiento inmediato. Se consideró que una muestra era adecuada para cultivo bacteriológico cuando tenía un volumen de 4 a $5 \mathrm{ml}$ y era lo suficientemente homogénea y fluida para llevar a cabo cultivos bacterianos cuantitativos.

Poblaciones bacterianas. Para el aislamiento e identificación de las poblaciones bacterianas se empleó la metodología sugerida por la American Society for Microbiology $(A S M)^{1}$ sin modificaciones: $100 \mu \mathrm{l}$ de cada una de las muestras de lavado broncoalveolar fueron sembrados por extensión en placas de Petri con agar Mac Conkey, agar gelosa sangre adicionado con sangre de carnero y agar SS e incubadas a $37^{\circ} \mathrm{C}$ durante $48-72 \mathrm{~h}$; posteriormente, se seleccionaron colonias con morfología sugestiva de $P$ aeruginosa que fueron resembradas en medios selectivos y diferenciales. Para la identificación del género y especie bacteriano se realizaron pruebas bioquímicas. En el caso de P aeruginosa, de cada muestra fueron aisladas al menos dos colonias y fueron clasificadas como mucoides o no mucoides (cepas $r$ y cepas $m$, respectivamente). De acuerdo con su morfología colonial en el primoaislamiento, cada colonia de $P$ aeruginosa con morfología colonial distinta se consideró como una cepa diferente aun cuando fuese aislada de la misma muestra.

Obtención del ADN bacteriano. Se realizaron cultivos de $P$ aeruginosa en $250 \mathrm{ml}$ de caldo Mueller Hinton incubados con agitación a $37^{\circ} \mathrm{C}$ durante 18 h; para la obtención del ADN se siguió la metodología sugerida por Schonian y colaboradores, sin modificaciones, ${ }^{28}$ la biomasa se obtuvo por centrifugación a $3500 \mathrm{xg}$ durante $10 \mathrm{~min}$ a $4{ }^{\circ} \mathrm{C}$; la pastilla se resuspendió en $3 \mathrm{ml}$ de amortiguador TE (Tris-HCl $10 \mathrm{mM}$, EDTA $1 \mathrm{mM}$ ) y se centrifugó a 1400 x g durante $10 \min$ a $4{ }^{\circ} \mathrm{C}$.

Las bacterias resuspendidas se incubaron en baño de hielo y se trataron con las siguientes soluciones: 2 $\mathrm{ml}$ de amortiguador de lisis (sacarosa $25 \%$, Tris- $\mathrm{HCl}$ $0.5 \mathrm{M}, \mathrm{pH}=8.0,500 \mu \mathrm{l}$ de EDTA $0.5 \mathrm{M}, 100 \mu \mathrm{l}$ de una solución de lisozima a una concentración de $50 \mathrm{mg} / \mathrm{ml}$ ), $2.5 \mathrm{ml}$ de Triton X 100 a $0.1 \%$, Tris- $\mathrm{HCl} 0.5 \mathrm{M} \mathrm{pH}=8.0$ y $500 \mu \mathrm{l}$ de acetato de potasio $5 \mathrm{M}$, se incubaron durante $30 \mathrm{~min}$ con las dos primeras soluciones y $10 \mathrm{~min}$ con el acetato de potasio; una vez lisado el cultivo bacteriano fue centrifugado a $15000 \mathrm{x}$ g durante $60 \mathrm{~min}$ y se resuspendió en $3 \mathrm{ml}$ de amortiguador TE.

Se realizaron tres extracciones vol/vol: la primera, con una mezcla de fenol saturado/cloroformo/alcohol isoamílico (25:24:1), la segunda extracción con cloroformo/alcohol isoamílico (24:1) y la tercera con cloroformo; entre cada extracción se mezcló y se centrifugó a 3500 x g durante $10 \mathrm{~min}$, recuperándose la fase acuosa en cada extracción. El ADN se precipitó con 2.5 volúmenes de etanol absoluto frío y se dejó reposar toda la noche a $-20^{\circ} \mathrm{C}$; posteriormente, se cen- 
trifugó durante 20 min a 7500 x g, se decantó y se adicionó etanol absoluto al 70\%; se centrifugó nuevamente durante 10 min a 3500 x g, se decantó, y la pastilla se deshidrató a temperatura ambiente, se resuspendió en amortiguador TE y se conservó a $-20^{\circ} \mathrm{C}$ hasta su utilización.

Con el propósito de obtener al ADN genómico libre de contaminantes los extractos totales de ADN se sometieron a electroforesis en agarosa a $1.0 \%$ y se purificó el ADN genómico empleando el sistema de QIAGEN (QIAGEN Inc, Valencia CA, EUA) de acuerdo con la metodología propuesta por el fabricante.

Amplificación del ADN bacteriano. Se utilizó la técnica de RAPD-PCR sugerida por Bulkanov y colaboradores, sin modificaciones ${ }^{21}$ y se seleccionaron los iniciadores 2162 y 2 163, recomendados por el mismo autor de acuerdo con los criterios de Kersulyte y Mahenthiralingam. ${ }^{22,23}$

\section{AN-2162:(5'-TGGTGGCCTCGAGCAAGAGAACGGAG-3') AN-2163:(5'-GGTTGGGTGAGAATTGC- 3')}

Se prepararon mezclas de reacción de $25 \mu \mathrm{l}$ con la siguiente composición: $30 \mathrm{ng}$ de $\mathrm{ADN}, 3 \mathrm{mM} \mathrm{MgCl}{ }_{2}$, 20 pmol de iniciador, 1 unidad de Taq polimerasa (GIBCO BRL, USA) y $250 \mu \mathrm{M}$ de cada dNTP en $10 \mathrm{mM}$ de Tris- $\mathrm{HCl}, \mathrm{pH}=8.3,50 \mathrm{mM} \mathrm{KCl}$ y $0.001 \%$ de gelatina.

Las condiciones de amplificación fueron las siguientes: 45 ciclos de incubación a $94{ }^{\circ} \mathrm{C}$ durante $1 \mathrm{~min}$, seguidos de 1 min a $36{ }^{\circ} \mathrm{C}$ y $72{ }^{\circ} \mathrm{C}$ durante 2 min y, finalmente, una incubación durante $10 \mathrm{~min}$ a $72{ }^{\circ} \mathrm{C} . .^{21}$ La amplificación se realizó en un amplificador marca Biometra modelo Biotron (Göttingen, Alemania).

Posteriormente, se tomaron alícuotas de $12 \mu \mathrm{l}$ y se sometieron a electroforesis en geles de agarosa a $2 \%$ que contenía bromuro de etidio $(0.5 \mu \mathrm{g} / \mathrm{ml})$ utilizándose una minicámara submarina modelo EC $370 \mathrm{M}$ y una fuente de poder EC 105 (EC Apparatus Corporation, EUA); como marcadores de peso molecular se utilizaron marcadores Bio-Rad Precision (Bio-Rad, Hercules CA, EUA); los geles fueron fotografiados utilizando un equipo Ultralum y, posteriormente, las fotografías fueron escaneadas y registradas empleando los programas ArcSoft Photo Studio 2000 (ArcSoft Inc EUA) y Power Point (Microsoft Corp, EUA).

Para la identificación de los patrones de amplificación de ADN se consideraron distintos a los que diferían en la presencia o ausencia de al menos dos bandas de amplificación, sin tomar en cuenta diferencias en las intensidades de tinción con bromuro de etidio. Los patrones de amplificación se realizaron en dos ocasiones para demostrar la reproducibilidad del método; como control positivo se utilizó ADN de una cepa de $P$ aeruginosa aislada de un paciente con FQ de la Asociación Mexicana de Fibrosis Quística y el ensayo se consideraba satisfactorio cuando, a partir del ADN control, se obtenían los patrones de amplificación característicos de la cepa.

\section{Resultados}

De septiembre de 1996 a junio de 2002 se estudiaron 163 muestras clínicas obtenidas de 64 pacientes con FQ que acudieron al SNCT-INPed para su diagnóstico y tratamiento; a partir de estas muestras se obtuvieron 165 aislamientos de $P$ aeruginosa, 59 de fenotipo mucoide y 106 de fenotipo no mucoide; es pertinente señalar que en un alto porcentaje de las muestras de lavado broncoalveolar se identificaron y aislaron dos cepas de $P$ aeruginosa mucoides (cepas $\mathrm{m}$ ) o no mucoides (cepas r) (datos no mostrados).

Del total de pacientes estudiados durante este periodo fueron seleccionados cinco con FQ para el presente proyecto (cuadro I); la edad de éstos varió de los 2 meses a los 22 años; fueron seleccionados pacientes con varias tomas de muestras de lavado broncoalveolar positivas al aislamiento de $P$ aeruginosa y que presentaban diferencias en su fenotipo (mucoide o no mucoide) el periodo de seguimiento varió de los dos meses a los tres años y se incluyó a una pareja de hermanos con FQ.

Se estudiaron 32 aislados de $P$ aeruginosa obtenidos a partir de los cinco pacientes seleccionados; como se observa en el cuadro I se incluyeron 12 aislados de fenotipo mucoide y 20 de fenotipo no mucoide.

Para la amplificación por RAPD-PCR se utilizaron los iniciadores 2162 y 2 163; se definieron 18 patrones de amplificación por RAPD-PCR, ocho de ellos con el iniciador 2162 y 10 con el iniciador 2 163, (cuadro I).

En las figuras 1 y 2 se muestran ejemplos de los patrones de amplificación para el caso de los aislados de $P$ aeruginosa provenientes del paciente G.G.L, y en la figura 3 se muestran los patrones de amplificación con el iniciador 2162 a partir del ADN de P aeruginosa aisladas del paciente C.G.L, hermano del anterior.

En la figura 1 se observa que cepas bacterianas aisladas de la misma muestra de lavado broncoalveolar mostraron patrones de amplificación distintos, éstos son los casos de las cepas $25 \mathrm{~m}$ y $25 \mathrm{r}$ y de las cepas $27 \mathrm{~m}$ y $27 \mathrm{r}$, pero así también las cepas 25 r y 27 m mostraron el mismo patrón de amplificación (2 162-C).

En la figura 2 se observa que las cepas $41 \mathrm{~m}$ y $41 \mathrm{r}$, que fueron aisladas de la misma muestra clínica, mos- 


\section{Cuadro I \\ Identificación de CEPAs de P AeRugin OSA AISLADAs de PACIENTES CON FIBRosis Quística en el Instituto Nacional de Pediatría, México, 1996-2000}

Nombre y edad inicial No. muestra Fecha aislamiento Fenotipo bacteriano Genotipo RAPD-PCR (iniciador 2 162) Genotipo RAPD-PCR (iniciador 2 163)

\begin{tabular}{llllll} 
1) G.G.L. 4 meses & 4 & $30-09-96$ & No mucoide & 2162-A & $2163-\mathrm{A}$ \\
\hline & 25 & $02-09-97$ & No mucoide / mucoide & $2162-\mathrm{C} / 2162-\mathrm{B}$ & $2163-\mathrm{A}$ \\
\hline 27 & $05-09-97$ & No mucoide / mucoide & $2162-\mathrm{C} / 2162-\mathrm{D}$ & $2163-\mathrm{A}$ \\
\hline 41 & $20-04-98$ & No mucoide / mucoide & $2162-\mathrm{C}$ & $2163-\mathrm{A}$ \\
\hline 48 & $05-08-98$ & No mucoide / mucoide & $2162-\mathrm{C}$ & $2163-\mathrm{B} / 2163-\mathrm{C}$
\end{tabular}

\begin{tabular}{llllll} 
2) C.G.L.6 años & 20 & $25-07-97$ & No mucoide & $2162-\mathrm{D}$ & $2163-\mathrm{D}$ \\
\hline & 38 & $27-03-98$ & No mucoide & $2162-\mathrm{C}$ & $2163-\mathrm{E}$ \\
\hline 45 & $04-06-98$ & No mucoide / mucoide & $2162-\mathrm{C} / 2162-\mathrm{B}$ & $2163-\mathrm{E} / 2163-\mathrm{F}$ \\
\hline 88 & $01-03-00$ & No mucoide / mucoide & $2162-\mathrm{C}$ & $2163-\mathrm{G}$ \\
\hline 102 & $05-05-00$ & No mucoide & $2162-\mathrm{C}$ & $2163-\mathrm{G}$ \\
\hline 106 & $04-07-00$ & No mucoide & $2162-\mathrm{C}$ & $2163-\mathrm{G}$
\end{tabular}

\begin{tabular}{llllll} 
3) C.P.H.22 años & 44 & $02-06-98$ & No mucoide / mucoide & $2162-\mathrm{E}$ & $2163-\mathrm{H}$ \\
\hline & 56 & $08-12-98$ & N o mucoide & $2162-\mathrm{E}$ & $2163-\mathrm{H}$ \\
\hline & 72 & $15-07-99$ & N o mucoide & $2162-\mathrm{E}$ & $2163-\mathrm{H}$
\end{tabular}

\begin{tabular}{|c|c|c|c|c|c|}
\hline 4) R.A.G. 1.2 años & 46 & $17-06-98$ & No mucoide & $2162-\mathrm{F}$ & 2163-I \\
\hline & 53 & $26-10-98$ & No mucoide & $2162-\mathrm{F}$ & 2163-I \\
\hline & 58 & $10-02-99$ & No mucoide / mucoide & $2162-F / 2162-G$ & 2163-I \\
\hline & 67 & 18-06-99 & No mucoide / mucoide & 2162-H & 2163-I \\
\hline & 69 & $25-06-99$ & No mucoide / mucoide & $2162-H$ & J \\
\hline 5) J.P.V. 2 meses & 22 & $11-08-97$ & No mucoide / mucoide & $2162-F$ & 2163-I \\
\hline & 30 & $24-10-97$ & Mucoide & $2162-\mathrm{F}$ & 2163-I \\
\hline
\end{tabular}

RAPD-PCR: técnica de la amplificación del ADN empleando PCR con bajas condiciones de especificidad

traron patrones de amplificación de ADN semejantes y que las cepas $48 \mathrm{~m}$ y $48 \mathrm{r}$ mostraron diferencias entre ellas.

Cuando se observan los patrones de amplificación obtenidos del paciente C.G.L. encontramos que las cepas 38 r y 45 m son semejantes (figura 3), pero lo más interesante es que presentan el patrón de amplificación 2 162-C que se observa en la cepa $25 \mathrm{~m}$, aislada del hermano.

Nuestros resultados muestran que, independientemente del fenotipo bacteriano, fue posible establecer la identidad de cada cepa de $P$ aeruginosa, lo que nos permitió obtener evidencias de infecciones cruzadas entre hermanos con FQ, así como demostrar la persistencia de aislamientos de cepas de $P$ aeruginosa con el mismo patrón de amplificación a partir de muestras de hermanos con FQ durante un periodo de tres años o bien a partir de sólo un paciente en muestras sucesivas de lavado broncoalveolar (cuadro I).

\section{Discusión}

La estrecha asociación entre $P$ aeruginosa y los pacientes con FQ ha sido descrita por distintos autores; ${ }^{1-5}$ la colonización del tracto respiratorio de los pacientes con FQ por parte de esta bacteria ocurre a edades tempranas y representa un serio problema que a largo plazo conduce a los individuos infectados a graves problemas de salud y, finalmente, a la muerte.

Los estudios de la epidemiología de $P$ aeruginosa en los enfermos con FQ tienen distintos tipos de problemas, varios de ellos derivados de las variaciones en el fenotipo de los aislados bacterianos a lo largo del periodo de infección. ${ }^{7,8,11}$ 


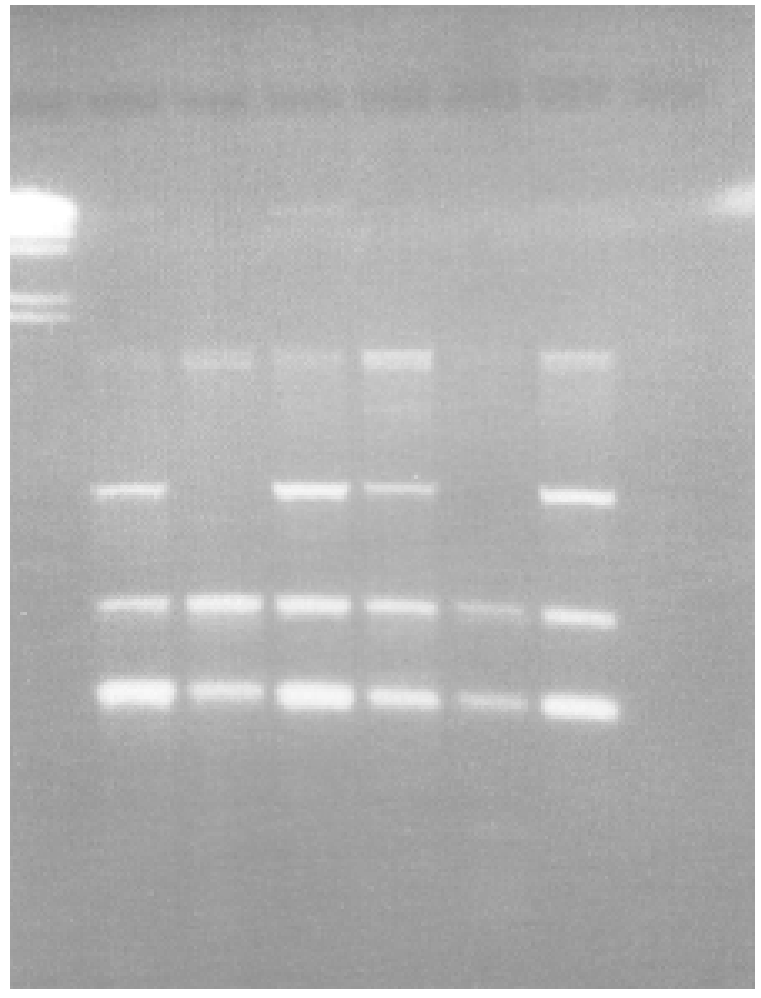

RAPD-PCR:técnica de la amplificación del ADN empleando PCR con bajas condiciones de especificidad

Figura 1. Patrones de amplificación por RAPD-PCR De Las Cepas de $P$ aeruginosa aisladas de pacientes CON FIBROSIS QUÍSTICA (G.G.L.), INICIADOR 2 162. CARRIL 1. MARCADORES DE PESO MOLECULAR; CARRIL 2. CEPA 4 R; CARRIL 3. CEPA 25 M, CARRIL 4. CEPA 25 R; CARRIL 5. CEPA 27 M; CARRIL 6. CEPA 27 R; CARRIL 7. CEPA 48 R; CARRIL 8. Control negativo. México, 1996-2000

Con los sistemas de identificación fenotípicos ha sido difícil establecer con certeza si un individuo presenta simultáneamente más de una cepa o clona de $P$ aeruginosa colonizando el tracto respiratorio; ha sido difícil definir si un paciente presenta reinfecciones por una misma cepa, si a lo largo del tiempo es infectado sucesivamente por cepas diferentes, o bien si existen diferencias entre las cepas aisladas de acuerdo con el sitio del tracto respiratorio del cual ha sido tomada la muestra para su análisis.

Con los sistemas fenotípicos de identificación bacteriana no ha sido posible estudiar de forma precisa la epidemiología de $P$ aeruginosa en los pacientes y las familias afectadas por FQ, lo que ha conducido al

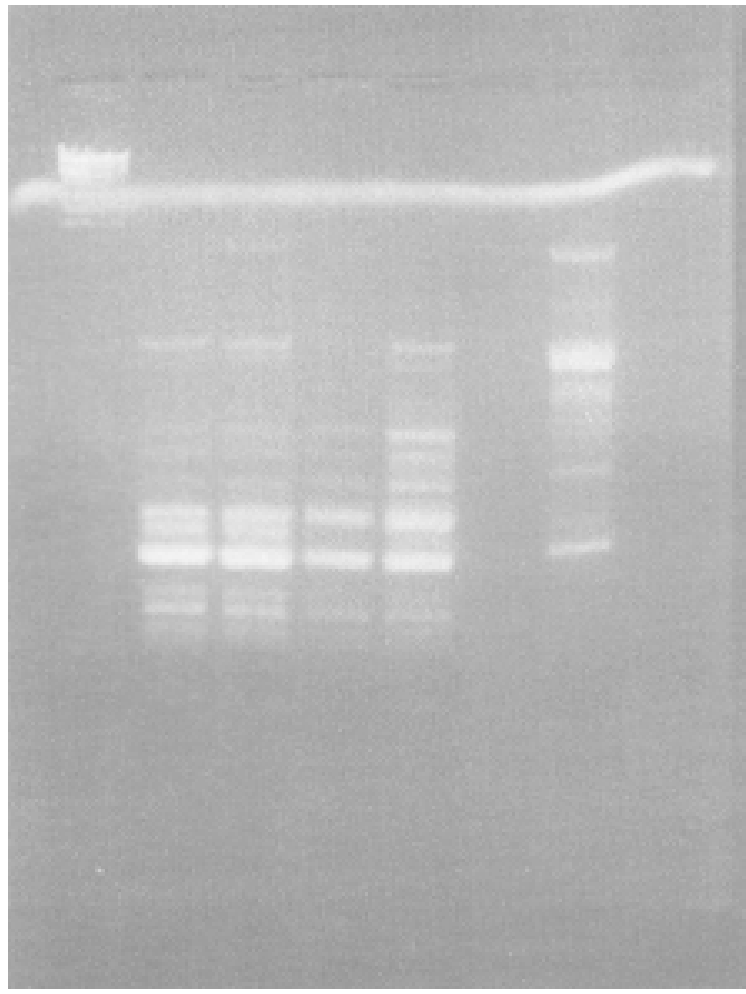

RAPD-PCR:técnica de la amplificación del ADN empleando PCR con bajas condiciones de especificidad

Figura 2. Patrones de Amplificación POR RAPD-PCR DE LAS CEPAS DE $P$ aERUGINOSA AISLADAS DE PACIENTES CON FIBROSIS QUISTICA (G.G.L.), INICIADOR 2 163. CARRIL 1. MARCADORES DE PESO MOLECULAR; CARRIL 2. CEPA $41 \mathrm{M}$; CARRIL 3. CEPA 41 R; CARRIL 4. CEPA 48 M; CARRIL 5. CEPA 48 R; CARRIL 6. CONTROL NEGATIVO, CARRIL 7. CONTROL POSITIVO. MÉXICO, 1996-2000

desarrollo de modelos de esta asociación huéspedparásitos que en ocasiones llegan a ser contradictorios entre sí. $7,8,11$

En la actualidad se prefiere el empleo de sistemas de identificación genotípicos los que han demostrado poseer una mayor sensibilidad y especificidad para la caracterización de las diferentes cepas o clonas bacterianas. ${ }^{17}$

Un sistema de identificación y caracterización genotípica que ha mostrado una gran sensibilidad y especificidad para definir los aislados bacterianos es el sistema de RAPD-PCR en el que se utilizan iniciadores arbitrarios bajo condiciones de baja especificidad; este sistema tiene la ventaja de ser más económico, rá- 


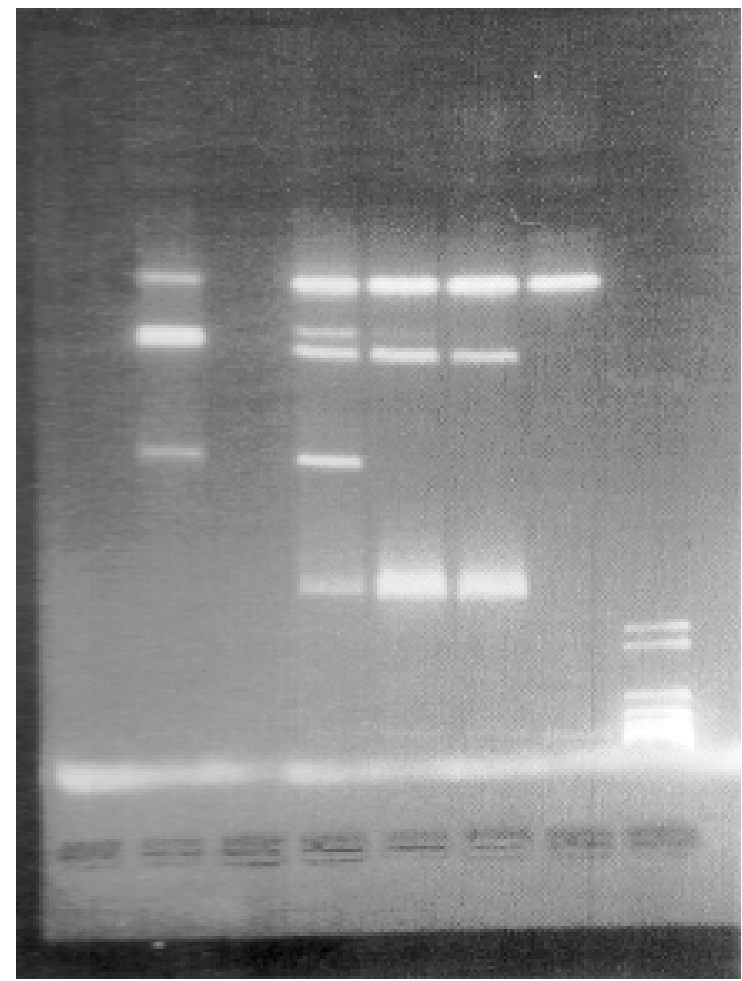

RAPD-PCR:técnica de la amplificación del ADN empleando PCR con bajas condiciones de especificidad

Figura 3. Patrones de amplificación por RAPD-PCR DE LAS CEPAS DE P. AERUGINOSA AISLADAS DE PACIENTES CON FIBROSIS QUÍSTICA (C.G.L.), INICIADOR 2 162. CARRIL 1. MARCADORES DE PESO MOLECULAR; CARRIL 2. CEPA 20 R; CARRIL 3. CEPA 38 R; CARRIL 4. CEPA 45 M; CARRIL 5. CEPA 45 R; CARRIL 6. CONTROL NEGATIVO; CARRIL 7. CONTROL POSITIVO. México, 1996-2000

pido y fácil de realizar que sistemas análogos, tanto fenotípicos como genotípicos. ${ }^{18,19}$

Los sistemas como la electroforesis de campos pulsantes y el RAPD-PCR difieren en el tipo de información que se puede derivar de ellos, ya que estudian secuencias diferentes y detectan tipos distintos de variaciones en el ADN del microrganismo; en este caso, RAPD-PCR detecta divergencias a través de todo el genoma bacteriano y no únicamente en secuencias particulares por lo que resulta de utilidad en la caracterización de aislados bacterianos a lo largo de periodos prolongados. ${ }^{14,21}$

En el caso de las cepas de $P$ aeruginosa asociadas a los pacientes con FQ se ha empleado el RAPD-PCR con éxito ${ }^{22-26}$ y ello nos llevó a plantearnos su utilización para la identificación de las cepas aisladas de nuestra población de enfermos con FQ, atendidos en el SNCT del INPed.

De la población total de pacientes estudiados durante el periodo de 1996 a 2000 se seleccionaron cinco considerando la presencia de aislamientos múltiples sucesivos lo que nos permitiría realizar un seguimiento de $P$ aeruginosa en nuestros enfermos; seleccionamos una pareja de hermanos con FQ para estudiar la posibilidad de intercambios de cepas bacterianas entre ambos; se seleccionaron a los dos pacientes con edades extremas de nuestro grupo (2 meses y 22 años) lo que nos permitiría estudiar una colonización temprana y una colonización crónica, y un enfermo fue seleccionado debido al número elevado de muestras en un periodo corto.

Es necesario mencionar que las muestras de lavado broncoalveolar de estos pacientes fueron tomadas durante sus visitas al Servicio de Neumología y Cirugía de Tórax (SNCT) y estas visitas obedecían a periodos de exacerbación del cuadro infeccioso, por lo que un mayor número de visitas al SNCT (y por lo tanto un número mayor de muestras para el estudio bacteriológico) refleja, en general, un proceso infeccioso agresivo y un estado de salud más deteriorado.

En nuestra población bacteriana destaca el elevado número de aislamientos de $P$ aeruginosa de fenotipo no mucoide ( $64 \%$ del total) lo que concuerda con los hallazgos de otros autores ${ }^{15,22,23}$ y que de alguna manera es contrario a la idea de que el fenotipo no mucoide es el que participa en las etapas iniciales de la colonización y que, posteriormente, es reemplazado por cepas de fenotipo mucoide, las que permanecen por periodos prolongados en el huésped, debido a su mayor adaptabilidad y capacidades agresivas.

Una de las explicaciones a nuestro hallazgo es el origen de la muestra analizada, ya que habitualmente el aislamiento de $P$ aeruginosa se lleva a cabo a partir de muestras de expectoración inducida y no de lavado broncoalveolar como en este caso. Las diferencias en el número de aislamientos de cepas con fenotipos distintos de acuerdo con el origen de la muestra clínica podría ser una evidencia de que efectivamente pueden presentarse variaciones en el fenotipo bacteriano, según el sitio del tracto respiratorio, de tal forma que las cepas no mucoides estarían mejor adaptadas a regiones más profundas del árbol respiratorio, mientras que las cepas mucoides colonizarían mejor a las regiones superiores.

Se observó que las diferencias en el fenotipo bacteriano no se relacionan con diferencias en el genotipo, es decir, cepas que en primoaislamiento son mucoides 
o no mucoides pueden, sin embargo, ser iguales desde el punto de vista de su patrón de amplificación por RAPD-PCR, y viceversa.

En el caso de los hermanos con FQ se observaron variaciones en los genotipos bacterianos a lo largo del periodo de estudio, predominando al final un genotipo bacteriano único; más interesante aún fue el hecho de que con el iniciador 2162 se obtuvieron evidencias que indican un posible intercambio de poblaciones bacterianas entre ambos pacientes.

Los pacientes 3 y 5 (22 años y 2 meses de edad, respectivamente) mostraron poblaciones bacterianas homogéneas desde el punto de vista genotípico; en el caso del paciente 3 posiblemente sea el resultado de una colonización bacteriana prolongada y de una selección de un genotipo más adaptado a las condiciones particulares del huésped, $\mathrm{y}$ en el caso del paciente 5 el proceso de selección posiblemente se encuentre en sus etapas iniciales, con una población bacteriana homogénea.

En todos los casos se demostró la persistencia de $P$ aeruginosa a pesar de que los pacientes (excepto el de 2 meses de edad) se encontraban en tratamiento con antibióticos, lo que es una evidencia de los altos niveles de resistencia a los antibióticos de las cepas de $P$ aeruginosa asociadas a los pacientes con $\mathrm{FQ}$.

Resulta preocupante el hecho de que nuestros pacientes con FQ se colonicen por $P$ aeruginosa a edades muy tempranas y que las poblaciones bacterianas permanezcan por periodos prolongados sin ser erradicadas y ocasionando reinfecciones frecuentes, lo que a largo plazo redunda en una menor calidad de vida de nuestros pacientes y en la selección de cepas o clonas más eficientes en su capacidad de permanencia en los huéspedes con FQ.

El presente reporte muestra que la identificación y caracterización mediante técnicas genotípicas de aislados de $P$ aeruginosa en poblaciones de pacientes con FQ seguidas a lo largo de varios años, permite estudiar con mayor precisión la epidemiología de esta bacteria en estos pacientes lo que facilita la evaluación de las medidas profilácticas, terapéuticas y de control de las poblaciones bacterianas.

\section{A gradecimientos}

Los autores desean agradecer a la médica especialista Jessica Banegas por su colaboración en la selección y manejo de los pacientes con fibrosis quística, a la Sra. Ofelia Ponce por su asistencia en la parte técnica y a la Dra. Alessandra Carnevale C, por su invaluable apoyo a lo largo de este proyecto.

\section{Referencias}

1. Kiska D L, Gilligan PH. Pseudomonas. En: Murray PR, Baron EJ, Pfaller $M A$, Tenover FC, Yolken RH, ed. Manual of clinical microbiology. $7^{\text {th }}$ edition.W ashington, DC:ASM Press; 1999:517-525.

2.W alker TS. Microbiology. Philadelphia (PA): O W B Saunders; 1998 :

173-181.

3. Z wadyk P. Pseudomonas. En: Joklil W K, W illet H P,Amos DB, W ilfert

CM Ed.Zinsser Microbiology. $20^{\text {th }}$ edition. California (CA):Appleton \& Lange; 1992:576-583.

4. Salyers AA,W hitt DD. Pseudomonas aeruginosa and related species, a lesson of versatility. En: Salyers AA,W hitt DD, ed. Bacterial pathogenesis, a molecular approach. $2^{\text {nd }}$ edition.W ashington, DC:ASM Press; 2002:247-262.

5. Muñoz-Elías EJ, McKinney JD. Bacterial persistence: Strategies for survival. En: Kaufmann SHE, Sher A, A hmed R, ed. Immunology of infectious diseases. W ashington, DC:ASM Press; 2002:331-355.

6. Snell JK, Bahner DR,W arren RL. Protease phenotypes of Pseudomonas aeruginosa isolated from patients with cystic fibrosis. J Clin Microbiol 1983:17:55-59.

7. W olz C, Kiosz G, 0 gle JW, Vasil ML, Schaad U, Botzenhart K et al. Pseudomonas aeruginosa cross-colonization and persistence in patients with cystic fibrosis. Use of a DN A probe. Epidemiol Infect 1989;102:205-214.

8. Horrevortz AM, Borst J, Puyk RJT, de Ridder R, Dzoljic-D anilovic G, Degener JE et al. Ecology of Pseudomonas aeruginosa in patients with cystic fibrosis. J Med Microbiol 1990:119-124.

9. Richardson CJL, BurkeV, Bailey M, Fisher A. Pyocin typing of Pseudomonas aeruginosa isolates from children with cystic fibrosis. Pathology 1991;23:229-232.

10. Zierdt CH,W illiams RL. Serotyping of Pseudomonas aeruginosa isolates from patients with cystic fibrosis of the pancreas. I Clin Microbiol 1975;1:521-526.

11. Kelly N M, Tempany E, Falkiner Fr, Fitzgerald MX, 0 'Boyle C, Keane CT. D oes Pseudomonas cross-infection occur between cystic fibrosis patients? Lancet 1982;ii:688-690.

12. 0 gle JW, Janda M,W ood DE,Vasil ML. Characterization and use of a DNA probe as an epidemiological marker for Pseudomonas aeruginosa.J Infect $D$ is 1987;155:119-126.

13. Grothues D, Koopman U, von der Hart H,Tümmler B. Genome fingerprinting of Pseudomonas aeruginosa indicates colonization of cystic fibrosis siblings with closely related strains. I Clin Microbiol 1988;26:1973-1977.

14. Struelen MJ, Schwam V, D eplano A, Baran D. G enome macrorestriction analysis of diversity and variability of Pseudomonas aeruginosa strains infecting cystic fibrosis patients. J Clin Microbiol 1993;31:2320-2326.

15. Römling U, Fiedler B, Bobhammer J, Grothues D, G eipel J, von der $\mathrm{H}$ art $\mathrm{H}$ et al. Epidemiology of chronic Pseudomonas aeruginosa infections in cystic fibrosis. J Infect D is 1994;170:1616-1621.

16. Zembrzuska-Sadkowska E, Sneum M, $O$ jeniyi B, Heiden L, H $\Delta$ iby N . Epidemiology of Pseudomonas aeruginosa infection and the role of contamination of the environment in the Danish cystic fibrosis center.J Hosp Infect 1995;29:1-7.

17.The International Pseudomonas aeruginosa Typing Study Group.A multicenter comparison of methods for typing strains of Pseudomonas aeruginosa predominantly from patients with cystic fibrosis. I Infect D is 1994;169:134-142.

18. W illiams JGK, Kubelik AR, Livak KJ, Rafalski JA, Tingey SV. D N A polymorphisms amplified by arbitrary primers are useful as genetic markers. N ucleic A cids Res 1990;18:6531-6535. 
19. Welsh J, McC lelland M. Fingerprinting genomes using PCR with arbitrary primers. N ucleic Acid Res 1990;18:7213-7218.

20. Bingen EH, W eber M, D erelle J, Brahimi N, Lambert-Zechovsky N Y, Vidailhet $M$ et al.Arbitrarily primed polymerase chain reaction as a rapid method to differentiate crossed from independent Pseudomonas cepacia infections in cystic fibrosis patients. J Clin Microbiol 1993;31:2589-2593

21. Bukanov N, N athan Ravi V, Miller D, Srivastava K, Berg DE. Pseudomonas aeruginosa corneal ulcer isolates distinguished using the arbitrarily primed PCR DNA fingerprinting method. Curr Eye Res 1994;13:783-790.

22. Kersulyte D, Struelens MJ, Deplano A, Berg DE. Comparison of arbitrarily primed PCR and macrorestriction (pulsed-field gel electrophoresis) typing of Pseudomonas aeruginosa strains from cystic fibrosis patients. J Clin Microbiol 1995;33:2216-2219.

23. Mahenthiralingam E, C ampbell ME, Foster J, Lam JS, Speert DP. Random amplified polymorphic DNA typing of Pseudomonas aeruginosa isolates recovered from patients with cystic fibrosis. J Clin Microbiol 1996;34:1129-1135
24. Renders N HM, Sijmons MAF, van Belkum A, 0 verbeek SE, Mouton JW, Verbrugh HA. Exchange of Pseudomonas aeruginosa strains among cystic fibrosis siblings. Res Microbiol 1997;148:447-454.

25. Hernández J, Ferrús MA, H ernández $M, 0$ wen RJ.Arbitrary primed fingerprinting and serotyping of clinical Pseudomonas aeruginosa strains. FEMS Immunol Med Microbiol 1997;17:37-47.

26. Adams C, Morris-Q uin M, McC onnell F,W est J, Lucey B, Short C et al. Epidemiology and clinical impact of Pseudomonas aeruginosa infection in cystic fibrosis using AP-PCR fingerprinting. I Infect 1998:37:151-158.

27. Cuevas Schacht F, Banegas-Matamoros J, Sosa de Martínez C, Coria-Jiménez VR, Pérez-Fernández L, G erónimo-G allegos $A$ et al. Identificación de Pseudomonas aeruginosa en pacientes pediátricos con fibrosis quística. Cultivo de expectoración vs lavado broncoalveolar. Acta Pediatr Mex 2001;22:419-423.

28. Schonian G, Grase Y, Meusel O, Bucholz P, Presber W, Mitchell G. Methods in DN A amplification. N ueva York: Plenum Press; 1994. 